\title{
Chemical Differences in Soil Organic Matter Fractions Determined by Diffuse-Reflectance Mid-Infrared Spectroscopy
}

\section{Francisco J. Calderón* \\ USDA-ARS \\ Central Great Plains Res. Stn. \\ 40335 County Rd. GG \\ Akron, CO 80720}

\section{James B. Reeves III}

USDA-ARS

Environmental Management and

Byproduct Utuilization Lab.

Room 117

10300 Baltimore Ave.

Bldg. 308 BARC-EAST

Beltsville, MD 20705

\section{Harold P. Collins}

USDA-ARS

Vegetable and Forage Crops

Research Lab.

24106 North Bunn Rd.

Prosser, WA 99350

\section{Eldor A. Paul}

Colorado State Univ.

Natural Resource Ecology Lab.

Fort Collins, CO 80523
We performed mid-infrared (MidIR) spectral interpretation of fractionated fresh and incubated soils to determine changes in soil organic matter (SOM) chemistry during incubation. Soils from four sites and three depths were processed to obtain the light fraction (LF), particulate organic matter (POM), silt-sized (silt), and clay-sized (clay) fractions. Our results show that the LF and clay fractions have distinct spectral features regardless of site. The LF is characterized by absorbance at $3400 \mathrm{~cm}^{-1}$, as well as between 1750 and $1350 \mathrm{~cm}^{-1}$. The clay fraction is distinguished by absorption near $1230 \mathrm{~cm}^{-1}$, and absorption at 780 to $620 \mathrm{~cm}^{-1}$. The POM, like the LF, absorbs at the broad peak at $1360 \mathrm{~cm}^{-1}$. High SOM soils are characterized by absorbance at $1230 \mathrm{~cm}^{-1}$, a band for aromatics, possibly associated with resistant $\mathrm{C}$. Soils from different sampling depths have specific spectral properties. $A$ band at $1330 \mathrm{~cm}^{-1}$ is characteristic of shallow depths. Because of their low organic matter $(\mathrm{OM})$ content, the deeper samples are characterized by mineral bands such as quartz, clays, and carbonate. Spectroscopic data indicates that the clay fraction and the LF suffered measurable chemical transformations during the 800-d incubation, but the POM and silt fraction did not. As the LF decomposes, it loses absorbance at 3400, 1223, and 2920 to $2860 \mathrm{~cm}^{-1}$. The band at $1630 \mathrm{~cm}^{-1}$ increased during incubation, suggesting a resistant form of organic $\mathrm{C}$. The clay fraction suffered changes that were opposite to those of the LF, indicating that LF decomposition and clay decomposition follow different chemistries.

Abbreviations: KBS, W.K. Kellogg Biological Station; LF, light fraction; MidIR, mid-infrared; MRT, mean residence time; OM, organic matter; POM, particulate organic matter; Py-MBMS, pyrolysismolecular beam mass spectrometry; SOC, soil organic carbon; SOM, soil organic matter.

U nderstanding SOM composition and cycling is fundamental because SOM contains large nutrient pools for crop growth, affects the soil physical properties necessary for roots to thrive, and can serve as a source or a sink for atmospheric $\mathrm{CO}_{2}$ (Lal, 2004). The stability of soil organic carbon (SOC) is determined by interactive effects of climate, parent material, soil depth, and agronomic management (Collins et al., 2000), and there is still much to be learned about OM quality and dynamics.

One approach to the study of SOM quality is fractionation by particle size and settling characteristics. The fractions consist of the LF made up of low density plant material, the POM included with the sand-sized material and protected C in aggregates, and the silt (silt) and clay-size (clay) separates (Haile-Mariam et al., 2008). Soil fractionation has given insight into the complexity of SOM, uncovering a range of $\mathrm{C}$ age, $\mathrm{N}$ content, and chemical makeup (Paul et al., 2001). In Corn Belt soils, the LF and POM contain relatively labile $\mathrm{C}$ and can comprise up to 5 and $11 \%$ of the SOC, respectively (Haile-Mariam et al., 2008). The LF contains plant residues and has a shorter $\mathrm{C}$ turnover time than the other particle-size fractions. In contrast, the silt and clay fractions tend to have more recalcitrant $\mathrm{C}$ than the other fractions (Christensen, 1987).

Extended laboratory incubations help characterize soils because the active C pools are transformed by microbial enzymes while the resistant SOC is less affected

Soil Sci. Soc. Am. J. 75:568-579

Posted online 18 Jan. 2011

Open Access Article

doi:10.2136/sssaj2009.0375

Received 1 Oct. 2009.

*Corresponding author (francisco.calderon@ars.usda.gov).

(C) Soil Science Society of America, 5585 Guilford Rd., Madison WI 53711 USA

All rights reserved. No part of this periodical may be reproduced or transmitted in any form or by any means, electronic or mechanical, including photocopying, recording, or any information storage and retrieval system, without permission in writing from the publisher. Permission for printing and for reprinting the material contained herein has been obtained by the publisher. 
(Collins et al., 2000; Haile-Mariam et al., 2008). Laboratory incubations are in effect a biological fractionation of SOC into active and slow pools, and they have been used to study the active, slow, and resistant soil fractions. Crop residue $\mathrm{C}$ is mineralized early in the incubation, with a mean residence time of about 100 d. In contrast, the slow $\mathrm{C}$ pool reflects the mid-range stability as well as management effects on SOC. Particle-size fractions may lose different proportions of SOC on incubation, underscoring the differences in $\mathrm{C}$ quality between them (Haile-Mariam et al., 2008). Incubations are especially useful when combined with tracer analysis or determination of specific chemical features.

Soils are an important factor of the Earth's $\mathrm{C}$ budget, but assessment of the size and dynamics of stable and labile $\mathrm{C}$ forms in soil are limited by labor intensive and costly methodologies. Fourier-transformed MidIR spectroscopy is a quick and nondestructive technology that has been used to calibrate for SOC in diverse sets of samples (McCarty and Reeves, 2000; Reeves et al., 2001; McCarty et al., 2002), indicating that the MidIR region contains spectral information related to a variety of soil chemical attributes. The MidIR region $\left(4000-400 \mathrm{~cm}^{-1}\right)$ is characterized by strong vibration fundamentals, and can be used for spectral interpretation of sample composition, because the MidIR spectra show peaks or bands that can be assigned to specific organic or mineral spectral bands (Nguyen et al., 1991; Haberhauer and Gerzabek, 1999; Baes and Bloom, 1989; Janik et al., 2007).

We need to be cautious when ascribing spectral bands to chemical features in environmental samples because myriad interactions with background materials can complicate spectral interpretation. Bands assignments are not absolute, in the sense that a band for a particular compound occurs exactly at a specific wavenumber. Bands even for functional groups in pure compounds are found over a range, and there is overlap between different functional groups. It should be noted that wet chemistry determinations of soil lignins, proteins, and other biopolymers are themselves hampered by technical hurdles, so a side-by-side comparison of spectral data and analyte data is often not practical. Studies with changes over time in the same soil are necessary, as one can try to see if what one observes relates to what might be expected with mineralization in the soil. Ash subtraction can potentially be very important in identifying organic or mineral absorption. However, the MidIR does contain a wealth of information and current research is shedding light on useful bands for the study of soil C quality. In their recent work on soil particle sizes, Bornemann and Amelung (2010) summarize the literature for structural assignments of several important bands (all in $\mathrm{cm}^{-1}$ ): 3600 to 3700 (OH of clay), 2850 to 2920 (ali- phatic C-H), 1700 ( $\mathrm{C}=\mathrm{O}$ of carbonyl C), 1660 (carbonyl C), 1630 (carboxyl C), 1600 to 1620 (phenolic compounds), 1565 (carboxyl C), 1500 to 1510 (aromatic $\mathrm{C}-\mathrm{H}$ and $\mathrm{C}=\mathrm{C}$ ), 1427 (carboxyl C), 1410 (aliphatic C), 1320 (hydroxylic C-O-H), 1250 (carboxylic COOH), 1160 (polysaccharides), 1000-1080 (C-O stretch of cellulose), and 870 (aromatic $\mathrm{C}-\mathrm{H}$ and $\mathrm{C}=\mathrm{C}$ ).

Soils analyzed by Haile-Mariam et al. (2008) provide a valuable sample set of fresh and incubated soils, including different soil types, sampling depths, and size fractions. We scanned the soil samples from continuous corn (Zea mays L.) rotations at four long-term study sites in the Corn Belt (Lamberton, Wooster, W.K. Kellogg Biological Station [KBS], and Hoytville). These four sites are among the oldest agronomic field experiments in the corn belt. Previous studies have given insight about the soil $\mathrm{C}$ age in these locations. Carbon dating of these sites using naturally occurring ${ }^{14} \mathrm{C}$ showed great increases in MRT at the lower depths and in those sites with more clays (Paul et al., 2001). The use of ${ }^{13} \mathrm{C}$ after the growth of continuous corn made it possible to calculate the amount and age of corn-derived materials (Collins et al., 1999; 2000). There was a high correlation between the ${ }^{13} \mathrm{C}$ and ${ }^{14} \mathrm{C}$ data, but the length of tracer exposure greatly affected the measured mean residence times (MRTs) leading to the suggestion that tracer studies report their data relative to the length of incubation. Fractionation before and after long-term incubation (Haile-Mariam et al., 2008) verified that the LF fraction turned over the fastest but also contained some old $\mathrm{C}$ present from the time before the growth of corn. All fractions, including the oldest clays, contained both young and old $\mathrm{C}$ showing the dynamic nature of all the constituents even though radiocarbon analysis indicated that the bulk soil SOM has mean residence times of hundreds of years.

Our objectives were to: (i) identify the spectral differences between the size fractions; (ii) subtract the ashed minus the whole soil spectra of a subset of samples to differentiate organic bands from mineral bands, (iii) compare the spectral data of the soil fractions before the incubation and carry out spectral interpretation to elucidate the chemical properties associated with the fractions, (iv) compare the spectral data of the whole (unfractionated) soils to determine spectral differences between depths and locations, (v) determine the effects of soil acidification-decalcification on spectral properties, and (vi) determine the spectral changes that occur due to decomposition during incubation.

\section{MATERIALS AND METHODS}

Samples were obtained from four agricultural experiments in the Corn Belt. The four sites formed in glacial deposits (Table 1). The KBS Michigan, Wooster Ohio, and Hoytville Ohio soils developed under

Table 1. Soil classification, parent material, and particle size.

\begin{tabular}{|c|c|c|c|c|c|c|}
\hline Site & Soil classification & Parent material & Sand & Silt & Clay & Organic C† \\
\hline & & & 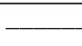 & $-\%$ & 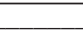 & $\mathrm{g} \mathrm{C} \mathrm{kg}^{-1}$ \\
\hline Wooster, $\mathrm{OH}$ & Typic Fragiudalfs & Glacial till & 22 & 59 & 19 & $10.6-15.6$ \\
\hline Hoytville, $\mathrm{OH}$ & Mollic Ochraqualfs & Lacustrine & 19 & 31 & 50 & $19.0-25.6$ \\
\hline Kellogg Biological Stn. (KBS), MI & Typic Hapludalfs & Glacial outwash & 43 & 38 & 19 & $10.9-11.5$ \\
\hline Lamberton, MN & Typic Haplustolls & Calcareous glacial till & 33 & 36 & 31 & 20.4 \\
\hline
\end{tabular}

tFrom Haile-Mariam et al. (2008). The range in the Wooster, Hoytvile, and KBS soils represent the values from tilled vs. no-till soils. 
deciduous hardwood forest, while the Lamberton Minnesota soils developed under grassland. Wooster, KBS, and Lamberton were started in agriculture in the 1800s, while Hoytville was not cultivated until the early 20th century once drainage issues were resolved. All four sites had been in continuous corn for at least $8 \mathrm{yr}$ before sampling.

Six cores $(5.4 \mathrm{~cm})$ were collected from each site to a depth of $1 \mathrm{~m}$ and depth sections were composited to make each field replicate. Four replicates were obtained from Lamberton and KBS, and three replicates from Wooster and Hoytville. The samples were sieved $(2 \mathrm{~mm})$ and plant debris was excluded. For this experiment, three depth increments were analyzed: 0 to 20,25 to 50 , and 50 to $100 \mathrm{~cm}$. A subset of soil samples was acidified to remove carbonates by mixing $20 \mathrm{~g}$ of soil with $100 \mathrm{~mL}$ of $250 \mathrm{mM} \mathrm{HCl}$, shaking for $1 \mathrm{~h}$, then washing three times with deionized water. The samples were centrifuged, dried at $55^{\circ} \mathrm{C}$, and ground $(180 \mu \mathrm{m})$. This resulted in soluble organic C losses of up to $10 \%$ (HaileMariam et al., 2008). Additional details about the sites, sampling, and analysis can be found in Collins et al. (2000).

Soil samples from the 0 - to $20-\mathrm{cm}$ depth were separated into particle-size fractions. The LF was obtained by mixing $10 \mathrm{~g}$ of soil with 40 $\mathrm{mL}$ of NaI solution ( $1.70 \mathrm{~g} \mathrm{~cm}^{-3}$ specific gravity), then the floating material was dried and ground before scanning. The soil material remaining after extracting the LF was rinsed three times with water, then shaken for $15 \mathrm{~h}$ in $30 \mathrm{~mL}$ of $5 \mathrm{~g} \mathrm{~L}^{-1}$ sodium hexametaphosphate. The POM plus sand was obtained by sieving $(53 \mu \mathrm{m})$ the dispersed samples. The material retained in the sieve was then dried at $60^{\circ} \mathrm{C}$ overnight. The silt and clay were obtained by sedimentation and decantation of the material that passed through the $53-\mu \mathrm{m}$ sieve.

The laboratory incubations were done with 25 -g samples ( 0 - to 20 cm depth) of each field replicate (Collins et al., 2000). The samples were brought to $60 \%$ of water holding capacity and stored in the dark. The incubation was designed to sample headspace $\mathrm{CO}_{2}$, so the containers were opened initially every $10 \mathrm{~d}$, and later every $\sim 21 \mathrm{~d}$. After each $\mathrm{CO}_{2}$ sampling, each container was restored to ambient $\mathrm{CO}_{2}$ with compressed air. After the incubation, each soil sample was air dried until fractionation using the above procedures (Haile-Mariam et al., 2008). Only the fraction samples (LF, POM, silt, and clay) were available after incubation.

All soil and soil fraction samples were scanned undiluted in MidIR on a Digilab FTS 7000 Fourier transform spectrometer (Varian, Inc., Palo Alto, CA) with a deuterated, Peltier-cooled, triglycine sulfate detector and potassium bromide beam splitter. The spectrometer was fitted with a Pike AutoDIFF diffuse reflectance accessory (Pike Technologies, Madison, WI) and $\mathrm{KBr}$ was used as background. Data was obtained as pseudo-absorbance $(\log [1 /$ Reflectance $])$. Spectra were collected at $4 \mathrm{~cm}^{-1}$ resolution, with 64 co-added scans per spectrum from 4000 to $400 \mathrm{~cm}^{-1}$. Duplicate scans of each sample were performed and included in the multivariate analyses.

Shallow $(0-20 \mathrm{~cm})$ and deep (50 cm plus) samples of whole soil from each of the four sites were scanned before and after ashing at $550^{\circ} \mathrm{C}$ for $3 \mathrm{~h}$. We used GRAMS/AI software, Version 7.02 (Thermo Galactic, Salem, NH) to perform spectral subtraction of ashed from unashed samples, to to bring out the OM spectral features and differentiate them from the mineral features (Cox et al., 2000, Sarkhot et al., 2007).

The whole sample set consisted of 354 samples, which included the different fractions, incubation times, and depths. Spectral differences between the sites, depths, decalcification, and fraction treatments were determined by principal components analysis (PCA) using the PLS Plus/IQ software in GRAMS/AI Ver. 7.02 (Thermo Galactic, Salem. $\mathrm{NH}$ ). All spectra were mean-centered and were pretreated with multiplicative scatter correction before the PCA analyses. The PCA scores were used for dimensionality reduction, while the component loadings were used to indicate which spectral bands explained the distribution of the sample scores along the principal components.

\section{RESULTS AND DISCUSSION Whole Soil and Fraction Spectra, Lamberton Site}

Data from the different fractions of the Lamberton site are displayed in Fig. 1 to show the appearance of the spectral features in the neat samples. The sharp peak at $3622 \mathrm{~cm}^{-1}$ indicates hydroxyl stretching in clays (Nguyen et al., 1991), and as expected, is prominent in the clay fraction. It is interesting that the LF absorbs in this region, forming a shoulder below the clay fraction. The broad band at $3400 \mathrm{~cm}^{-1}$, pronounced in the LF, is due to $\mathrm{OH}$ or $\mathrm{NH}$ stretching typical in crop residues (Haberhauer and Gerzabek, 1999). The LF contributes 0.5 to $0.8 \mathrm{~g} \mathrm{C} \mathrm{kg}^{-1}$ and makes up 3 to $5 \%$ of the SOC, and isotope analysis has shown that the LF is an active fraction that contains recent plant residue C (Haile-Mariam et al., 2008). The feature between 2950 and $2870 \mathrm{~cm}^{-1}$ is attributed to aliphatic $\mathrm{CH}$ stretching (Janik et al., 2007). A series of three peaks between 2000 and $1790 \mathrm{~cm}^{-1}$, present in the whole soil, silt fraction, and POM, but absent in the LF, mark the presence of quartz in sand (Nguyen et al., 1991). The 1700 to $1250 \mathrm{~cm}^{-1}$ spectral region has concentrated information about many important functional groups. This region indicates differences between the soil fractions, as well as the general similarity between the POM and the silt (Fig. 1). The feature near 1730 to $1700 \mathrm{~cm}^{-1}$ is due to esters and carboxylic acids (Haberhauer and Gerzabek 1999; Cox et al., 2000; Janik et al., 2007; Sarkhot et al., 2007). It forms a shoulder on the stronger broad band at $1650 \mathrm{~cm}^{-1}$ in the LF, although it leads to a peak near $1690 \mathrm{~cm}^{-1}$ in the POM and silt fractions (Fig. 1).

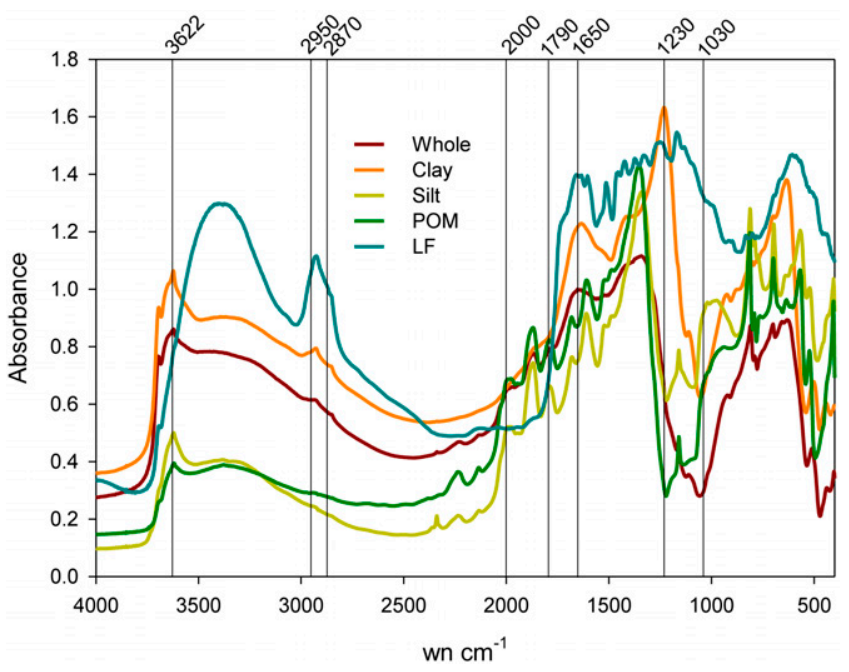

Fig. 1. Mid-infrared spectra of unincubated whole soil and particle size fractions $(0-20 \mathrm{~cm}$ depth) from Lamberton, MN. POM, particulate organic matter; LF, light fraction; wn, wavenumbers in $\mathrm{cm}^{-1}$. 
Bands at $1610 \mathrm{~cm}^{-1}$ are due to aromatic $\mathrm{C}=\mathrm{C}$ (Baes and Bloom, $1989)$, those at $1650 \mathrm{~cm}^{-1}$ are due to protein. Note that these bands occurring between 1600 and $1650 \mathrm{~cm}^{-1}$ for lignin and protein are broad and overlapping, so one must use caution in how this region is interpreted. It is possible that on the LF absorbance in this region is affected by amide linkages. In older soil fractions it could be due to absorbance of lignin-like materials. When absorbance at 1600 to $1650 \mathrm{~cm}^{-1}$ increases together with absorbance at $1510 \mathrm{~cm}^{-1}$, it may indicate an accumulation of aromatic recalcitrant material. Note also that this region may have silica interference due to the silica band near $1610 \mathrm{~cm}^{-1}$. The LF and clay absorb highly in this region, while the POM and silt show a peak at $1610 \mathrm{~cm}^{-1}$ (Fig. 1). The LF has a peak at 1510 $\mathrm{cm}^{-1}$ indicating aromatic $\mathrm{C}=\mathrm{C}$, a feature that is also present in the stable fractions of OM like humic and fulvic acids (Baes and Bloom, 1989). The spectrum of the Lamberton whole soil has a broad peak between 1460 and $1270 \mathrm{~cm}^{-1}$. Fractionation allowed us to resolve some of the absorbance bands in this region. The $\mathrm{LF}$ absorbs at the $\mathrm{CH}_{2}$ and the $\mathrm{CH}_{3}$ bending bands at 1450 and $1400 \mathrm{~cm}^{-1}$ (Fig. 1). These alkyl deformation bands are also important for total organic C determination in soils (Janik et al., 2007). The region between 1380 and $1270 \mathrm{~cm}^{-1}$ in the whole soils consists of mostly mineral material according to ashing analysis (see below). This is a region of relatively high absorbance in the Lamberton fractions and whole soil, but forms well defined peaks in the silt and POM. The band for aromatic ring $\mathrm{C}-\mathrm{H}$ forms a pronounced peak at $1230 \mathrm{~cm}^{-1}$ in the Lamberton clay fraction, but shows little absorbance in the POM (Fig. 1). This band is present in oxidized black $\mathrm{C}$, and is useful in soil $\mathrm{C}$ determinations (Janik et al., 2007). The region 1080 to 1050 is present as an inversion band in the spectra of soils rich in silicates and clays, due to specular reflectance of quartz (Nguyen et al., 1991). Figure 1 shows a dip in absorbance at this band in the whole soil, POM, clay, and silt. The LF absorbs at the $1030 \mathrm{~cm}^{-1}$ carbohydrate/polysaccharide band relative to the rest of the frac-

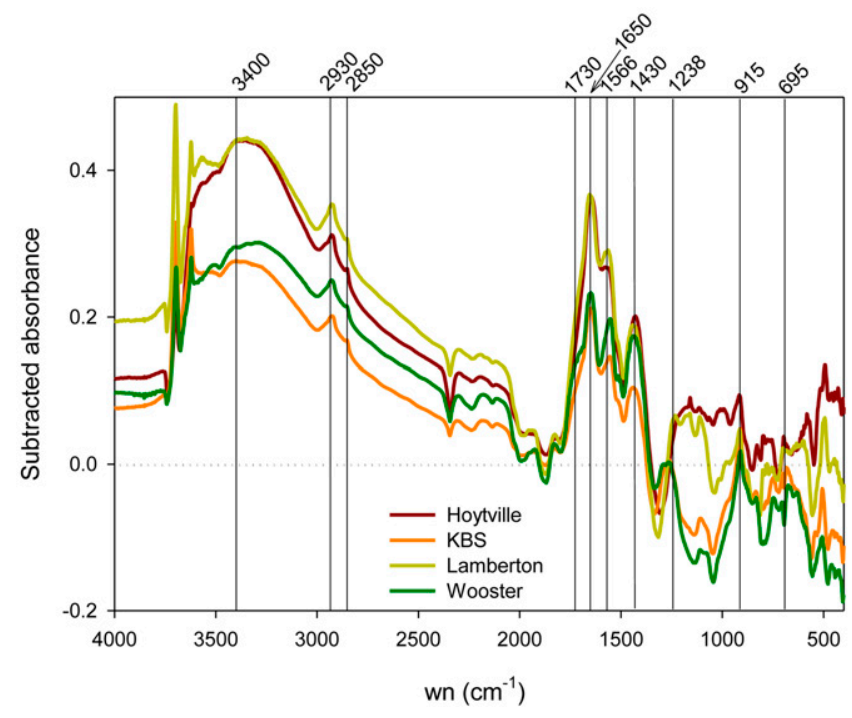

Fig. 2. Spectral subtraction results of the whole soil (neat) spectra minus the ashed soil spectra, 0 - to $20-\mathrm{cm}$ depth; wn, wavenumbers in $\mathrm{cm}^{-1}$. tions. The region below $1000 \mathrm{~cm}^{-1}$ is a mixture of organic and mineral bands best resolved by a spectral subtraction of whole (neat) minus ashed spectra (below).

\section{Spectral Subtraction of the Whole Soils minus the Ashed Soils}

Figure 2 shows the spectral subtraction of the neat soil minus the ashed soil for the four Corn Belt sites. The higher absorbance values in the graph denote spectral regions where organic features dominate. The high OM soils from Lamberton and Hoytville (Table 1) have the highest values throughout most of the spectral range (Fig. 2). Sharp dips due to the water bands from dehydrated clays can be seen at 3739 and $3674 \mathrm{~cm}^{-1}$. The large peak at $3400 \mathrm{~cm}^{-1}$, which is high in the LF (Fig. 1) has the highest absorbance in the high OM soils from Hoytville and Lamberton (Fig. 2). The $\mathrm{CH}$ bands at 2930 and $2850 \mathrm{~cm}^{-1}$, also high in the LF (Fig. 1), are from aliphatic $\mathrm{CH}$ stretching indicative of SOM (Haberhauer and Gerzabek, 1999; Janik et al., 2007). The bands at 2160,2100, and $1940 \mathrm{~cm}^{-1}$ are possibly from proteins, as we have observed them in albumin and gelatin in our laboratory (data not shown). Shoulders at $1730 \mathrm{~cm}^{-1}$ are due to carbonyls in esters (Sarkhot et al., 2007), which are part of the easy to decompose organic C. Absorbance at $1650 \mathrm{~cm}^{-1}$ is a combined band from proteins and probably lignin and humic acids, all of which absorb between 1660 and $1610 \mathrm{~cm}^{-1}$. Where this band appears in a sample depends on the ratios and concentrations of the contributors. The band at $1566 \mathrm{~cm}^{-1}$ is from proteins and is due to the amide II band in SOM (Janik et al., 2007). The organic peak at $1430 \mathrm{~cm}^{-1}$ is possibly another combination band due to $\mathrm{CH}$ bending and deformation, and $\mathrm{C}-\mathrm{O}$ vibrations (Haberhauer and Gerzabek, 1999). It is observable in aromatic compounds, lignin, and proteins. The organic band at

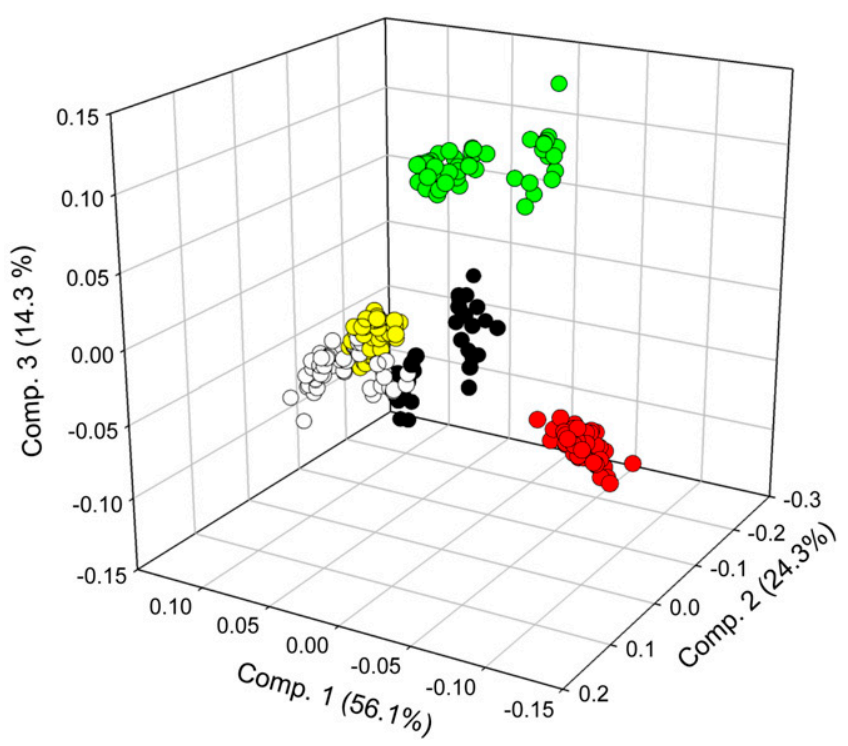

Fig. 3. Principal components analysis of the neat Mid-infrared spectra of unincubated soil and particle size fractions, the 0 - to $20-\mathrm{cm}$ depth. All sites together. Light fraction in red, whole soil in black, particulate organic matter in white, silt in yellow, and clay in green. The percentage of the spectral variance accounted for each component is in parenthesis. 
$1238 \mathrm{~cm}^{-1}$ could be due to aromatic- $\mathrm{CH}$ in plane deformation and has high partial least squares regression loadings for TOC (Janik et al., 2007). This band could also be due to lignin and carbohydrate C-O bands.

Spectral interpretation is challenging between 1400 and $400 \mathrm{~cm}^{-1}$ because bands could be due to several mineral or organic chemicals (Fig. 2). Janik et al. (1998) assign peaks below $1300 \mathrm{~cm}^{-1}$ to kaolinite and quartz, but Janik et al.(2007) indicate that peaks in the $<1400 \mathrm{~cm}^{-1}$ region could also be suggestive of cellulose or lignin. Spectral subtraction shows that the aromatic ring $\mathrm{CH}$ band at 1238 to $1230 \mathrm{~cm}^{-1}$ may actually be a mineral band in low OM soils (Fig. 2). The Lamberton and Hoytville soils absorb between 1030 and $1160 \mathrm{~cm}^{-1}$ as an organic band, whereas the KBS and Wooster have mineral bands in this region (Fig. 2). Sarkhot et al. (2007) found absorbance at $1160 \mathrm{~cm}^{-1}$ band in soil aggregates. The bands below $1000 \mathrm{~cm}^{-1}$ are mostly mineral in the low SOM KBS and Wooster soils. Lamberton and Hoytville, however, have possibly organic spectral features below $1000 \mathrm{~cm}^{-1}$. The region from 950 to $700 \mathrm{~cm}^{-1}$ contains many bands due to different linkages in carbohydrates, with a minor influence from lignin and proteins. Janik et al. (1998) found that absorbance at $915 \mathrm{~cm}^{-1}$, probably due to aromatics and high in the LF (Fig. 1), has high loadings for the prediction of soil C. Our subtraction approach shows that this peak could be due to organic absorption in all four Corn Belt sites (Fig. 2). Spectral subtraction of the neat-ashed Lamberton soils shows the following minor peaks that should be organic but cannot be assigned to specific organic bands: $494 \mathrm{~cm}^{-1}$ (present in the clay fraction), and 603 to $598 \mathrm{~cm}^{-1}$ (Fig. 1).

\section{Comparison of Soil Fractions at Time Zero}

Figure 3 shows the PCA of the whole soil and fractions at time zero, for all sites. The PCA indicates that size fractions have spectral differences that override site differences. The POM and silt have similar spectral properties and clustered very closely according to their PCA scores. The clay fraction and the light fraction have distinct spectral properties, forming separate clusters from the rest of the fractions.

The LF has low scores along Component 1, and loadings indicate high absorbance in the following regions: The broad $\mathrm{OH} / \mathrm{NH}$ band at $3400 \mathrm{~cm}^{-1}$, the aliphatic and aromatic $\mathrm{CH}$ band at 2950 to $2840 \mathrm{~cm}^{-1}$, the aromatic ring $\mathrm{CH}$ band at $1223 \mathrm{~cm}^{-1}$, and a peak near $490 \mathrm{~cm}^{-1}$ (Fig. 4). These features are prominent in the LF spectrum from the Lamberton site (Fig. 1). The LF also absorbs at the $\mathrm{O}-\mathrm{Si}-\mathrm{O}$ quartz inversion region, indicating low quartz content.
Particulate OM makes up 5 to $23 \%$ of the SOC, with the smaller proportions in the fine-textured soils at Lamberton and Hoytville (Haile-Mariam et al., 2008). The POM, and to a lesser extent the silt, have high scores along Component 1, opposite to the LF. Loadings indicate that POM and silt differ from LF in
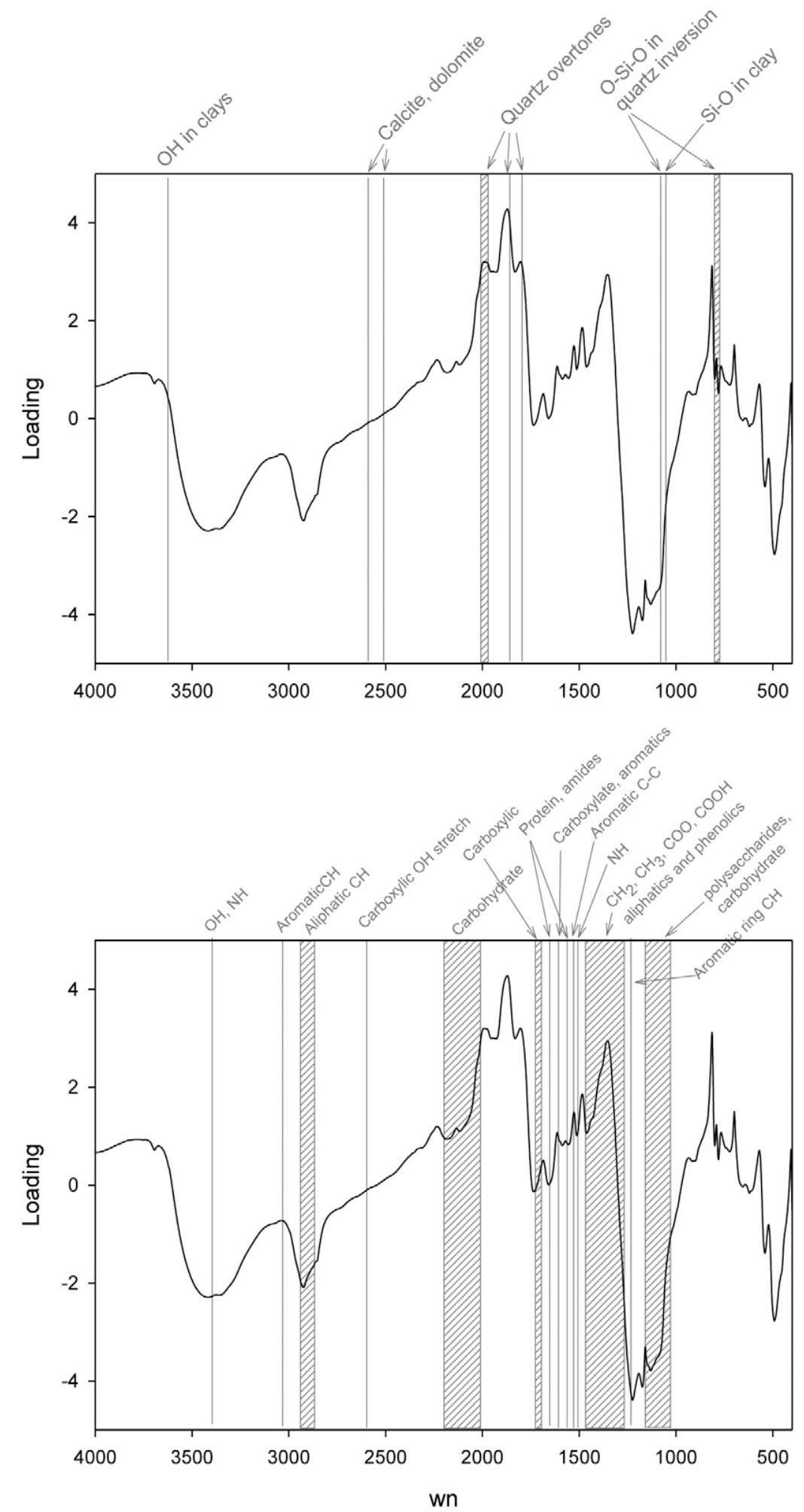

Fig. 4. Component 1 loadings for the principal components analysis of the neat mid-infrared spectra of unincubated soil and soil fractions shown in Fig. 3; wn, wavenumbers in $\mathrm{cm}^{-1}$. Top graph has the mineral bands indicated, bottom graph has the organic bands. 
the above mentioned bands, and also because higher absorbance at the 2000 to $1790 \mathrm{~cm}^{-1}$ quartz overtone region, and a peak near $814 \mathrm{~cm}^{-1}$, a band observed in lignin, but shown to be of possible mineral origin in the whole soil spectra (Fig. 2). The POM
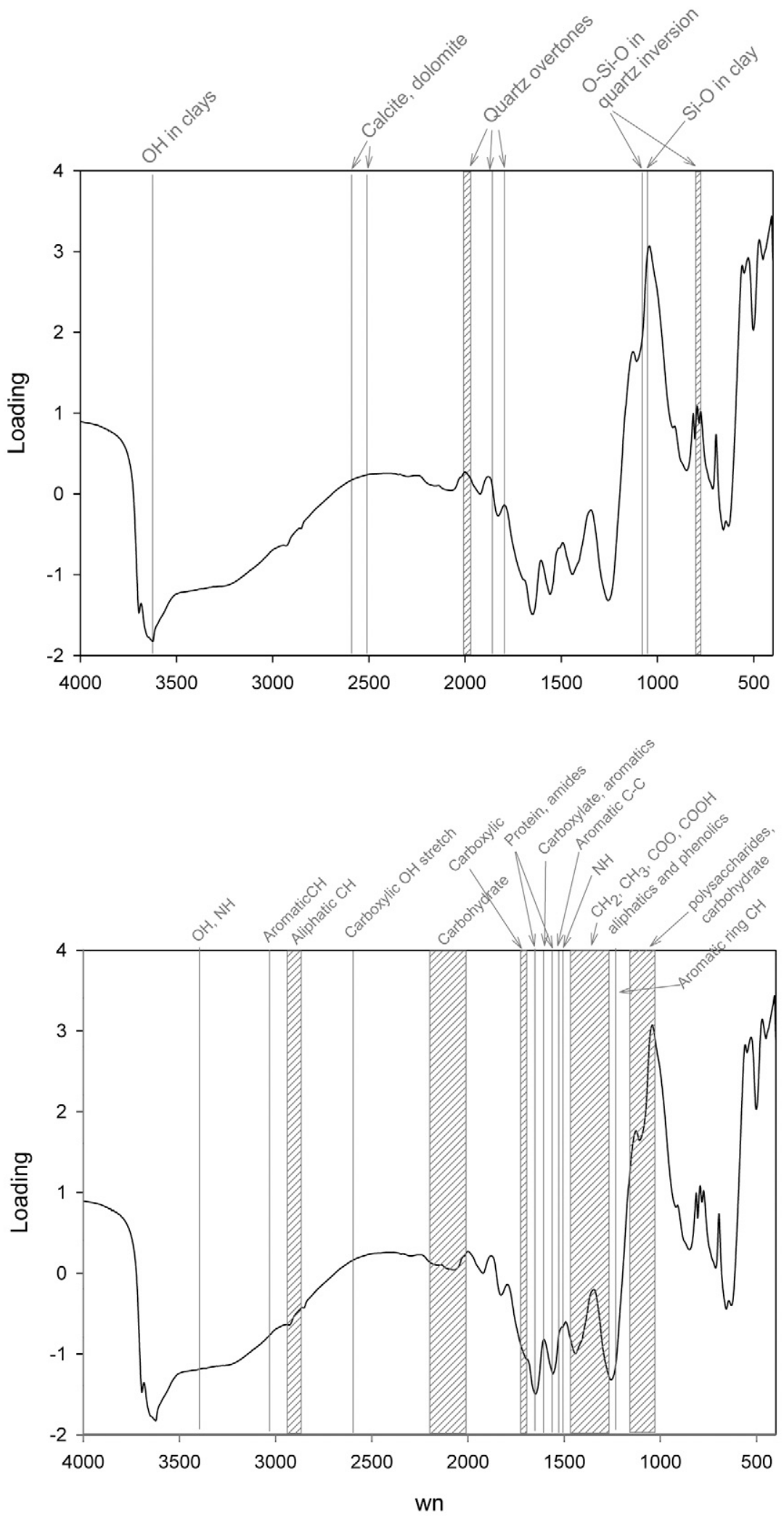

Fig. 5. Component 2 loadings for the principal components analysis of the neat midinfrared spectra of unincubated soil and soil fractions shown in Fig. 3; wn, wavenumbers in $\mathrm{cm}^{-1}$. Top graph has the mineral bands indicated, bottom graph has the organic bands. fraction contains a large amount of sand, explaining the quartz overtone band. The PCA results agree with the Lamberton fraction data (Fig. 1). The POM and silt absorb more than the LF at $1360 \mathrm{~cm}^{-1}$, at the region for $\mathrm{CH}_{2}, \mathrm{CH}_{3}, \mathrm{COO}$, and $\mathrm{COOH}$ absorbance in aliphatics.

The whole soil and clay, specifically those of Hoytville and Lamberton, tended to have low scores along Component 2 (Fig. 3), although spectral diversity was relatively high in these two fractions. Loadings indicate that Hoytville and Lamberton clay and whole soils tend to be characterized by low absorbance at the $1080 \mathrm{~cm}^{-1}$ quartz O-Si-O inversion band (Fig. 5). Loadings also indicate the Hoytville and Lamberton whole soil and clay also absorb at the $3400 \mathrm{~cm}^{-1} \mathrm{OH} /$ $\mathrm{NH}$ stretching band, and as expected, at the clay $\mathrm{OH}$ stretching band at $3600 \mathrm{~cm}^{-1}$. The Hoytville and Lamberton whole soil and clay are also characterized by absorbance at a broad region between 1750 and $1350 \mathrm{~cm}^{-1}$, which includes bands for many organic $\mathrm{C}$ functional groups such as carboxylic, proteins, amides, aliphatic, and aromatic $\mathrm{C}$ bonds. Component 2 loadings indicate that the silt, LF, and POM, absorb at the band near $1050 \mathrm{~cm}^{-1}$ (Fig. 5). This band can indicate polysaccharide binding agent in soil aggregates (Sarkhot et al., 2007).

The silt and clay fraction comprise up to 16 to $28 \%$ and 36 to $68 \%$ of the total SOM respectively, with the highest values in the Lamberton samples. The silt and clay fractions contain the oldest $\mathrm{C}$ according to mean residence time, which is more stable than LF and POM (Table 2). Component 3 clearly separates the clay particles with high scores from the rest of the fractions (Fig. 3). The loadings for Component 3 indicate that clay fractions are characterized by absorbance at a pronounced peak at the aromatic ring $\mathrm{CH}$ or carbohydrate band near $1230 \mathrm{~cm}^{-1}$, and a broad band between 780 and $620 \mathrm{~cm}^{-1}$ (Fig. 6). The 780 to $620 \mathrm{~cm}^{-1}$ band was also observed in the clay spectrum from Lamberton (Fig. 1), and Fig. 2 shows that it could be of mineral or organic origin depending on the sample site.

Table 2 shows isotopic and $\mathrm{C}$ data for the Hoytville soil fractions from Haile-Mariam et al. (2008). The difference of the $\mathrm{C} / \mathrm{N}$ ratio from 19 in the LF to 6.5 in the clay suggests the greater composition of carbohydrate in the LF and protection of proteinaceous materials in the clay (Table 2). When corrected for fixed ammonia, the $\mathrm{C} / \mathrm{N}$ ratio of the clay would still be below 8 , suggesting the occurrence of proteinaceous type material in this fraction. This corroborates 
theories that amino compounds are closely associated with clay surfaces (Sollins et al., 2006). However, we did not find strong spectral amino signals in the clay fraction. The clay samples form two groups in Fig. 3 because the Lamberton clays are spectrally different from the rest of the clays (not shown). This suggests that there are compositional differences between prairie-derived clay from forest-derived clay fractions.

Silt has older C3-derived C than the POM (Haile-Mariam et al., 2008, Table 2), yet the POM and silt spectra are relatively similar. A closer look at the PCA in Fig. 3 shows that there are some differences between them. The POM tends to have higher Component 1 scores, and lower Component 2 and 3 scores relative to the silt fraction (Fig. 3). Component loadings indicate that POM has a tendency for higher absorbance than the silt at the broad peak around $1348 \mathrm{~cm}^{-1}$, that indicates aliphatics and phenolics. The POM also tends to absorb more than the silt fraction at the 2000 to $1790 \mathrm{~cm}^{-1}$ quartz band, and at the $3622 \mathrm{~cm}^{-1}$ clay band (Fig. 4). The silt fraction absorbs higher than the POM at the aromatic ring $\mathrm{C}-\mathrm{H}$ deformation band near $1223 \mathrm{~cm}^{-1}$ (Fig. 1 and 6).

\section{All Sites and Depth, Time Zero Comparison, Unfractionated Soils}

The PCA shows that spectral differences between depths are apparent even when all the sites are analyzed together (Fig. 7). Component 3 loadings indicate that the 0 - to $20-\mathrm{cm}$ depth absorbs more at the $\mathrm{CH}$ bending region near $1330 \mathrm{~cm}^{-1} \mathrm{com}$ pared with the deeper soils (data not shown). Figure 2, however, suggests this is possibly a mineral band in the surface soils. The deeper samples, especially those from KBS and Lamberton both have high loadings along Component 3, indicating high absorbance in the quartz overtone region, the $3622 \mathrm{~cm}^{-1}$ clay band, and the calcite/dolomite band at $2517 \mathrm{~cm}^{-1}$.

The PCA in Fig. 7, when coded by site instead of depth, shows that KBS and Wooster samples are separated along Component 2 from the Hoytville and Lamberton samples (not shown). The Lamberton and Hoytville soil are high SOC soils with high clay content, while the KBS and Wooster soils are alfisols of relatively low clay content and low SOC (Paul et al., 2001; Haile-Mariam et al., 2008) (Table 1). Component 2 loadings show that Lamberton and Hoytville absorb highly at $1230 \mathrm{~cm}^{-1}$ (data not shown). This suggests that this band, high in the clay fraction from Lamberton (Fig. 1) marks samples with high SOC. Note that KBS and Wooster topsoils may have mostly mineral absorption in this region (Fig. 2). Janik et al. (2007) showed that the absorbance at $1230 \mathrm{~cm}^{-1}$ is characteristic of SOM, and is an important input to total organic $\mathrm{C}$ prediction models. Absorbance at $1230 \mathrm{~cm}^{-1}$ has been attributed to aromatics. However, we did not find that absorbance at $1230 \mathrm{~cm}^{-1}$ was accompanied by absorbance at 1610 to $1620 \mathrm{~cm}^{-1}$, suggesting that this signal represents carbohydrate or more likely mineral clay. Compared with Lamberton and Hoytville soils, KBS and Wooster have low absorbance at the $3622 \mathrm{~cm}^{-1}$ clay OH band, but absorb highly at the quartz
Table 2. Characteristics of the Hoytville soil fractions. Data recalculated from Haile-Mariam et al. (2008). MRT = mean residence time.

\begin{tabular}{lcccc} 
& LF & POM & Silt & Clay \\
\hline 0 d C distribution, \% & 3.5 & 8.4 & 23.1 & 52.9 \\
800 d C distribution, \% & 1.0 & 13.8 & 25.5 & 50.8 \\
C to N ratio & 19.6 & 15.0 & 10.3 & 6.5 \\
0 d ${ }^{13}$ C \% & -14.1 & -17.8 & -22.4 & -23.5 \\
C $_{3}$-C \% & 16 & 45 & 80 & 89 \\
C $_{4}$ MRT yr & 3.7 & 7.8 & 12.8 & 26.0 \\
C $_{3}$ MRT yr & 17.0 & 38.0 & 139.0 & 261.0 \\
\hline
\end{tabular}
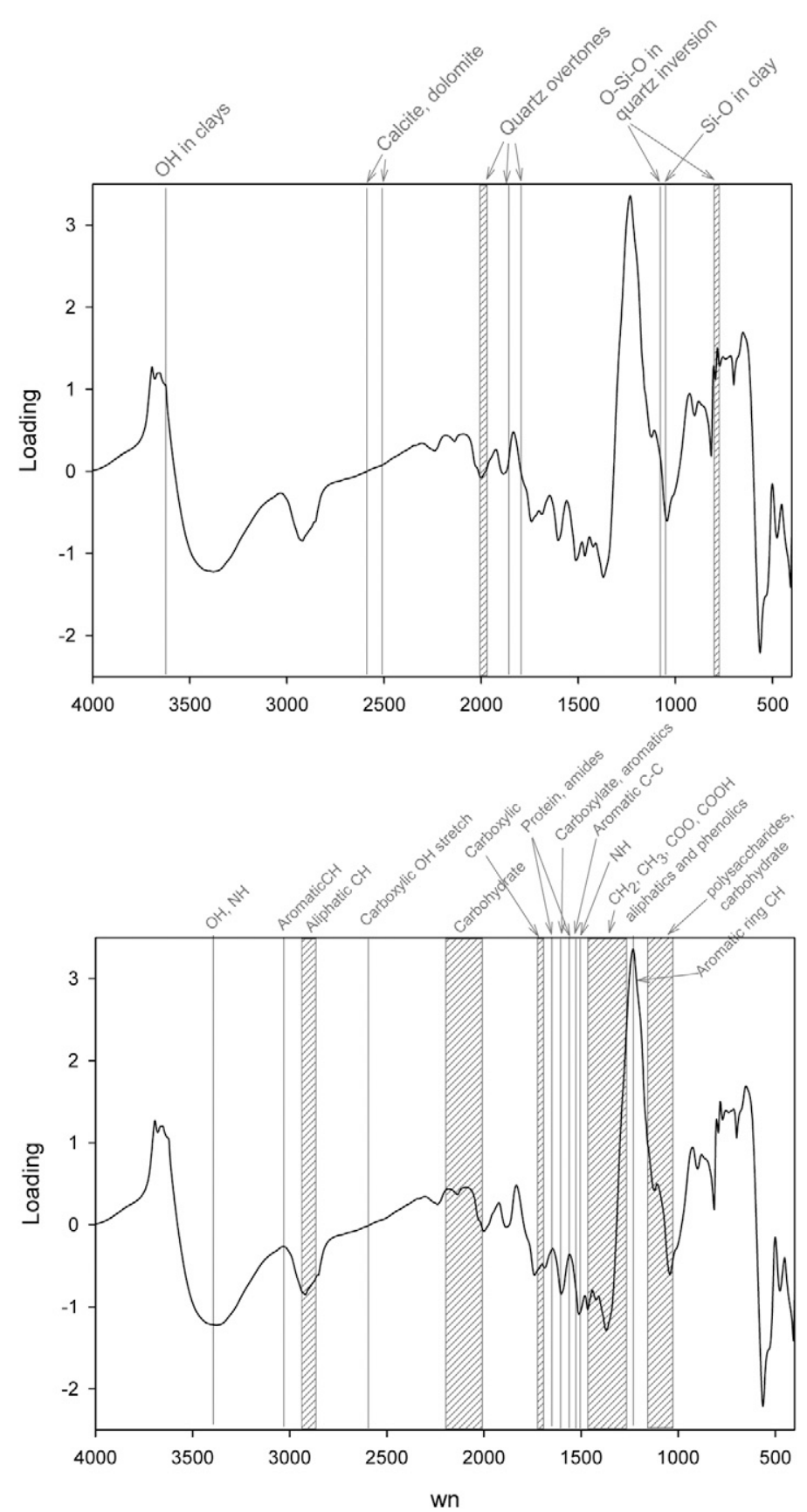

Fig. 6. Component 3 loadings for the principal components analysis of the neat mid-infrared spectra of unincubated soil and soil fractions shown in Fig. 3; wn, wavenumbers in $\mathrm{cm}^{-1}$. Top graph has the mineral bands indicated, bottom graph has the organic bands. 
overtone region at 1080 and 800 to $780 \mathrm{~cm}^{-1}$, the $1050 \mathrm{~cm}^{-1}$ polysaccharide band, and the $\mathrm{CH}$ band at $1370 \mathrm{~cm}^{-1}$.

\section{Comparison of Decalcified Soils with Untreated Soils}

The PCA analysis showed spectral differences between the untreated and decalcified samples for all four sites. In KBS, Lamberton, and Hoytville, the separation was clear with decalcification, while in the Wooster soils the separation occurred only when examining each depth individually (not shown). In the Lamberton samples the difference between decalcified and untreated spectra was more pronounced for deeper layers (Fig. 8).

In all sites, component loadings showed that the decalcification increased absorption at the $\mathrm{CH}$ bending region between 1450 and $1370 \mathrm{~cm}^{-1}$ characteristic of surface soils. Acidification decreased absorption at the clay $\mathrm{OH}$ stretching band near $3600 \mathrm{~cm}^{-1}$. It is possible that the acidification and washing process removed sesquioxide clays from the sample, explaining the drop in absorbance at $3600 \mathrm{~cm}^{-1}$. The acidification may have also removed portions of the SOM. For example, in the Hoytville and Lamberton samples, acidification also reduced absorption at the $1223 \mathrm{~cm}^{-1}$ aromatic $\mathrm{C}-\mathrm{H}$ band.

The Lamberton soils are the only ones that actually show a decrease in the calcite/dolomite band near $2517 \mathrm{~cm}^{-1}$ (data not shown). Lamberton, like the Hoytville soil, formed on calcareous parent material and have B horizons containing calcium carbonate. The Lamberton soil, however, has more mineral $\mathrm{C}$ below $50 \mathrm{~cm}$, with $5.7 \mathrm{~g} \mathrm{~kg}^{-1}$ compared with $1.8 \mathrm{~g} \mathrm{~kg}^{-1}$ for Hoytville (Paul et al., 2001). The KBS soils in turn, has little mineral $\mathrm{C}$ at all depths (Paul et al., 2001), and as expected there was no effect on the calcite/dolomite bands with acidification on the KBS soils.

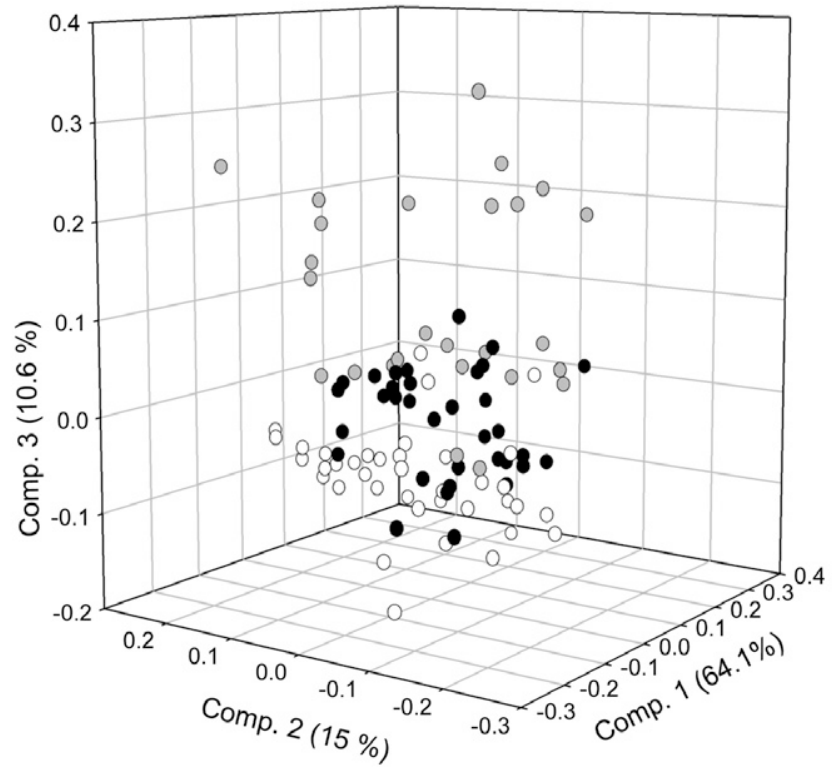

Fig. 7. Principal components analysis of the neat Mid-infrared spectra of unincubated and unfractionated soil. All samples from the KBS, Wooster, Hoytville, and Lamberton included. White is 0 to $20 \mathrm{~cm}$, black is 25 to $50 \mathrm{~cm}$, gray is $50+\mathrm{cm}$. The percentage of the spectral variance accounted for each component is in parenthesis.

\section{Changes of Soil Fraction Spectra during Incubation}

The PCA results show that the clay and light fraction spectra changed during laboratory incubation (Fig. 9 and 10). The spectral properties of the POM and silt fractions were little affected by incubation (data not shown). For the LF and clay, including all sites still showed good separation between incubation times, indicating that the type of spectral changes during incubation were observed across sites (Fig. 9 and 10).

Component loadings show that the LF loses absorbance during incubation at the $3400 \mathrm{~cm}^{-1} \mathrm{OH} / \mathrm{NH}$ band, the 2920 to $2860 \mathrm{~cm}^{-1} \mathrm{CH}$ band, the region between 900 and $1200 \mathrm{~cm}^{-1}$ that includes the aromatic $\mathrm{C}-\mathrm{H}$ band, and a band near $480 \mathrm{~cm}^{-1}$ (Fig. 11). The losses of absorbance in the $\mathrm{OH}$ area, and in the area between 900 and $1200 \mathrm{~cm}^{-1}$ (due to $\mathrm{Si}-\mathrm{O}$ inversion, but not in the LF) are consistent with carbohydrate materials being lost over time. The results confirm observations by others that the $3400 \mathrm{~cm}^{-1}$ band marks decomposable plant material (Haberhauer and Gerzabek, 1999; Janik et al., 2007). Likewise, Spaccini et al. (2001) found that the aliphatic bands in the 2920 to $2860 \mathrm{~cm}^{-1}$ regions can be used to study mineralization rates of corn residues in soil. During LF incubation, bands for clay $\mathrm{OH}$, carboxylate/aromatics at $1630 \mathrm{~cm}^{-1}$, and protein/amide $\left(1650\right.$ and $\left.1570 \mathrm{~cm}^{-1}\right)$ increase. It is possible that the spectral signatures for mineral bands and recalcitrant $\mathrm{C}$ become prominent during decomposition as the labile organic material is mineralized and lost from the sample. The increase in protein could be explained by the growth of the microbial biomass and production of microbial proteins during incubation. Calderón et al. (2006) found that infrared bands associated with proteins increased during manure incubation. Besides the production of microbial proteins, the spectral data suggests that there is an enrichment in highly aromatic $\mathrm{C}$. Increase in the aromatic band

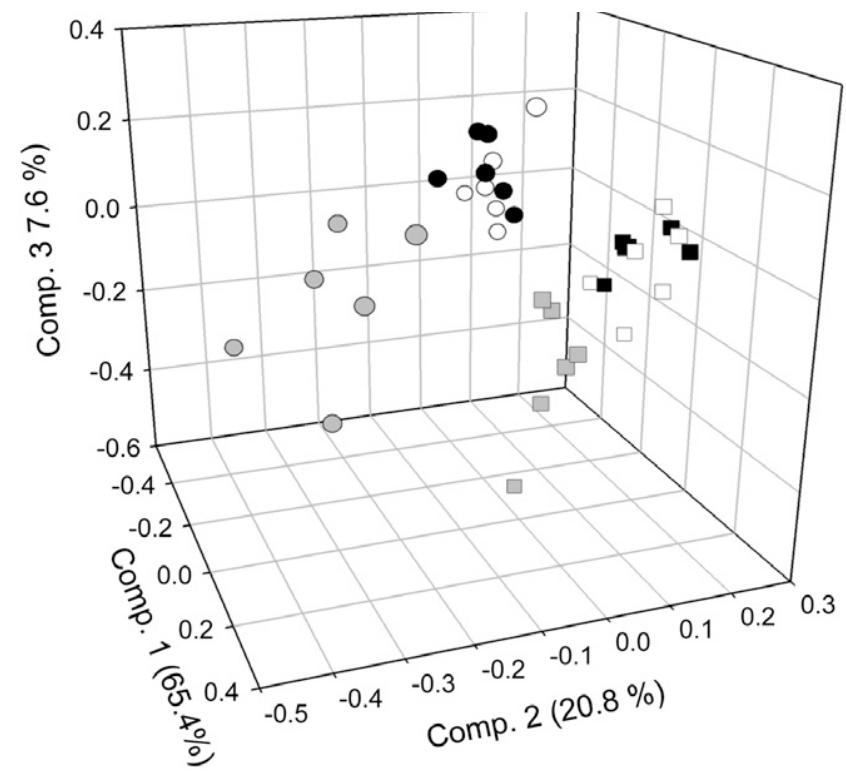

Fig. 8. Principal components analysis of the Lamberton time zero samples. Square samples are decalcified, circles are untreated. Gray are $50+\mathrm{cm}$ depth, black are $25-$ to $50-\mathrm{cm}$ depth, and white are the 0 - to $20-\mathrm{cm}$ depth. The percentage of the spectral variance accounted for each component is in parenthesis. 
suggest that humic acids are left over after the easily degraded $\mathrm{C}$ is removed. Artz et al. (2006) used the ratio of 1600/1030 (carboxylate/polysaccharide) as an index of decomposition in peat, suggesting that the band near 1630 represents a relatively recalcitrant form of organic C, probably a combination of lignin and humics. The previous study with this set of soils, as exemplified by the data in Table 2, showed that the LF lost more $\mathrm{C}$ than the other size fractions, confirming that the LF contains labile plant and microbial material, and can be responsible for short-term soil fertility (Haile-Mariam et al., 2008). The LF C decreased $65 \%$ on average during the $800-\mathrm{d}$ incubation, and some of the LF C was transferred to other fractions.

Our spectral analysis showed that the LF fraction contained some clay. We can use previous data from this experiment (HaileMariam et al. (2008) to calculate the contribution of the per kilogram clay-associated $\mathrm{C} 3-\mathrm{C}$ to the ${ }^{13} \mathrm{C}$ value of $-13.9 \%$ in the $\mathrm{LF}$ fraction (Table 2). The LF of this soil had $360 \mathrm{~g} \mathrm{C} \mathrm{kg}^{-1}$ relative to $420 \mathrm{~g} \mathrm{C} \mathrm{k} \mathrm{g}^{-1}$ in the added corn stover (data not shown). The clay contained $20 \mathrm{~g} \mathrm{C} \mathrm{kg}^{-1}$. Thus $<1 \%$ of the $\mathrm{C}$ of the $\mathrm{LF}$ can be attributed to clay-associated $\mathrm{C}$. This indicates that although LF is shown by MidIR to contain some clay, it also contained other forms of stabilized $\mathrm{C}$ not associated with clay. One example could be charcoal. Additional studies are needed to elucidate these observations.

The clay fraction accounts for the largest portion of total soil C in these Corn Belt soils, so changes in clay C quality during laboratory incubation could have important implications for large-scale soil C dynamics. There was a change in SOC distribution during the incubation with a drop in both the LF and clay fractions in spite of the fact that the clay has the oldest MRTs for both the corn-derived C4 and original forest-derived C3 components (Table 2). Component 2 of the clay fraction PCA shows

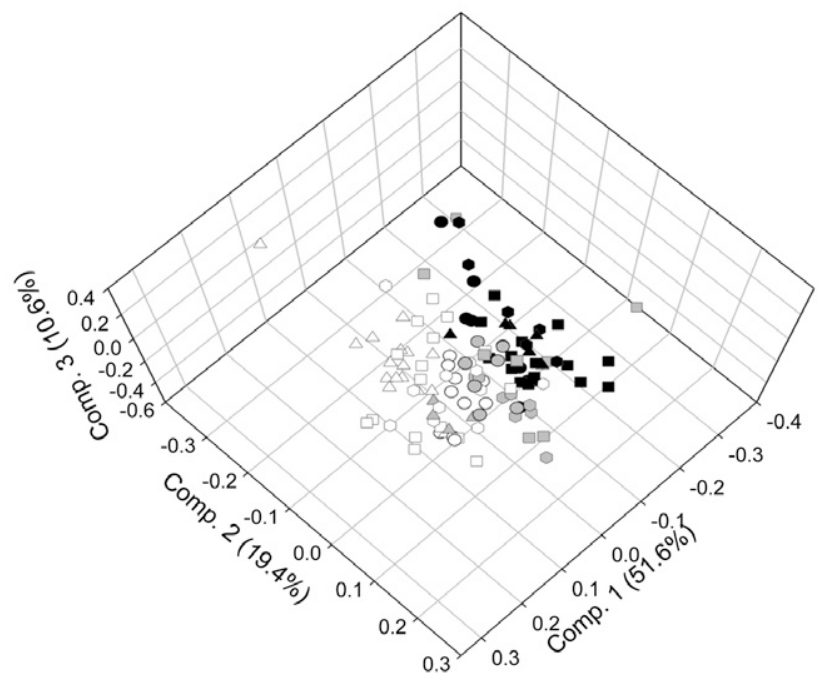

Fig. 9. Principal components analysis of the light fraction samples. All four sites are included. W.K. Kellogg Biological Station samples are squares, Lamberton samples are triangles, Hoytville samples are circles, and Wooster samples are hexagons. Time zero is white, samples incubated for $\mathbf{4 4 0} \mathrm{d}$ are gray, and $800-\mathrm{d}$ incubation are black. The percentage of the spectral variance accounted for each component is in parenthesis. that during incubation, the clay fraction loses absorbance at the quartz overtone bands between 1800 and $2000 \mathrm{~cm}^{-1}$, and the $\mathrm{CH}$ deformation band between 1270 and $1460 \mathrm{~cm}^{-1}$ (Fig. 12). The 1460 to $1270 \mathrm{~cm}^{-1}$ region is high in the Lamberton clay fraction (Fig. 1), but is shown to contain some mineral bands in the whole soil spectra (Fig. 2). Absorbance losses at $1730 \mathrm{~cm}^{-1}$ suggest losses of carbonyls in esters, which should be relatively easy to split during decomposition. The clay increases in absorbance at a prominent band near $1205 \mathrm{~cm}^{-1}$, and at the $3400 \mathrm{~cm}^{-1} \mathrm{OH} /$ $\mathrm{NH}$ band. Spectral changes of the clays are mostly the reverse of the patterns obtained during the LF incubation throughout most of the MidIR spectral range, demonstrating that LF decomposition follows a very different chemistry than the transformations of the clay fraction. Specifically the following spectral changes in the clays during incubation are opposite to the spectral changes in the LF: (i) increase in the $\mathrm{OH} / \mathrm{NH}$ band at $3400 \mathrm{~cm}^{-1}$, (ii) decrease in the carbohydrate band at 2200 to $2000 \mathrm{~cm}^{-1}$, (iii) decrease throughout a large spectral region between 1730 and $1250 \mathrm{~cm}^{-1}$ that includes bands for aromatics, aliphatics, amides, proteins, phenolics, and (iv) decrease in absorbance in the region between 650 and $100 \mathrm{~cm}^{-1}$ and the peak at $479 \mathrm{~cm}^{-1}$. HaileMariam et al. (2008) showed that the clay C concentration did not change as much as the LF during the incubation, although there was a small decline in the Hoytville soil. Table 2 shows that clay has the oldest $\mathrm{C}$ for both corn and noncorn derived SOC, suggesting that the clay fraction can be considered very stable and highly processed compared with the rest of the size fractions. We hypothesize that the spectroscopic changes in the clay fraction are explained mostly by a change in the quality of the organic material, instead of the amount of C lost.

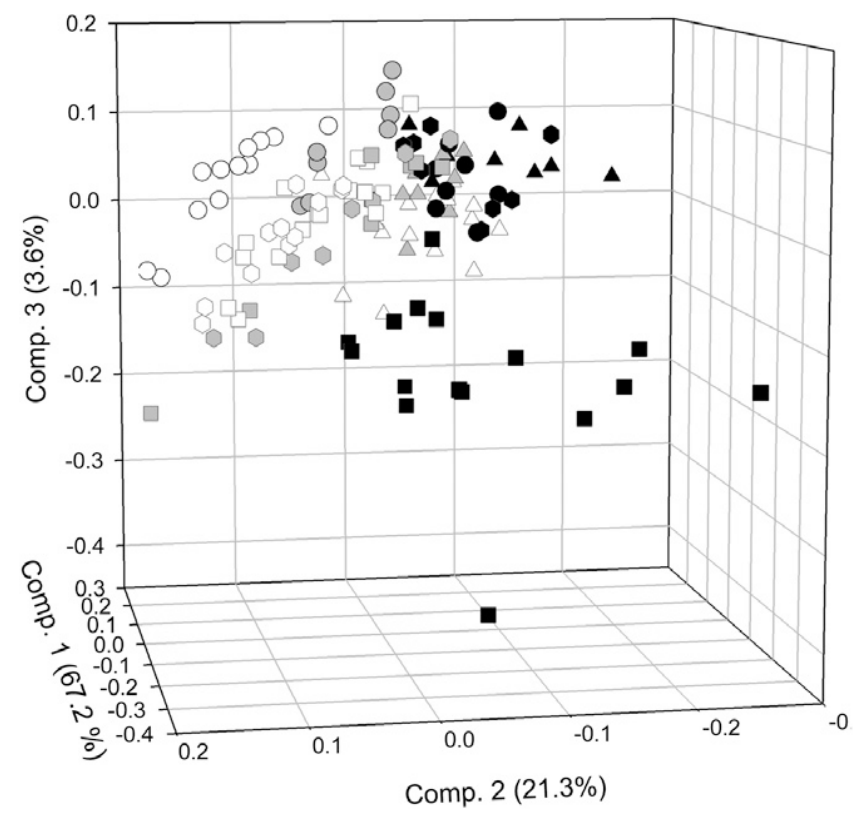

Fig. 10. Principal components analysis of the clay-sized fraction samples. All four sites are included. W.K. Kellogg Biological Station samples are squares, Lamberton samples are triangles, Hoytville samples are circles, and Wooster samples are hexagons. Time zero is white, samples incubated for $\mathbf{4 4 0} \mathrm{d}$ are gray, and 800-d incubation are black. The percentage of the spectral variance accounted for each component is in parenthesis 


\section{CONCLUSIONS}

This study used MidIR to measure the functional groups and absorbing bonds of both $\mathrm{OM}$ and soil mineral constituents
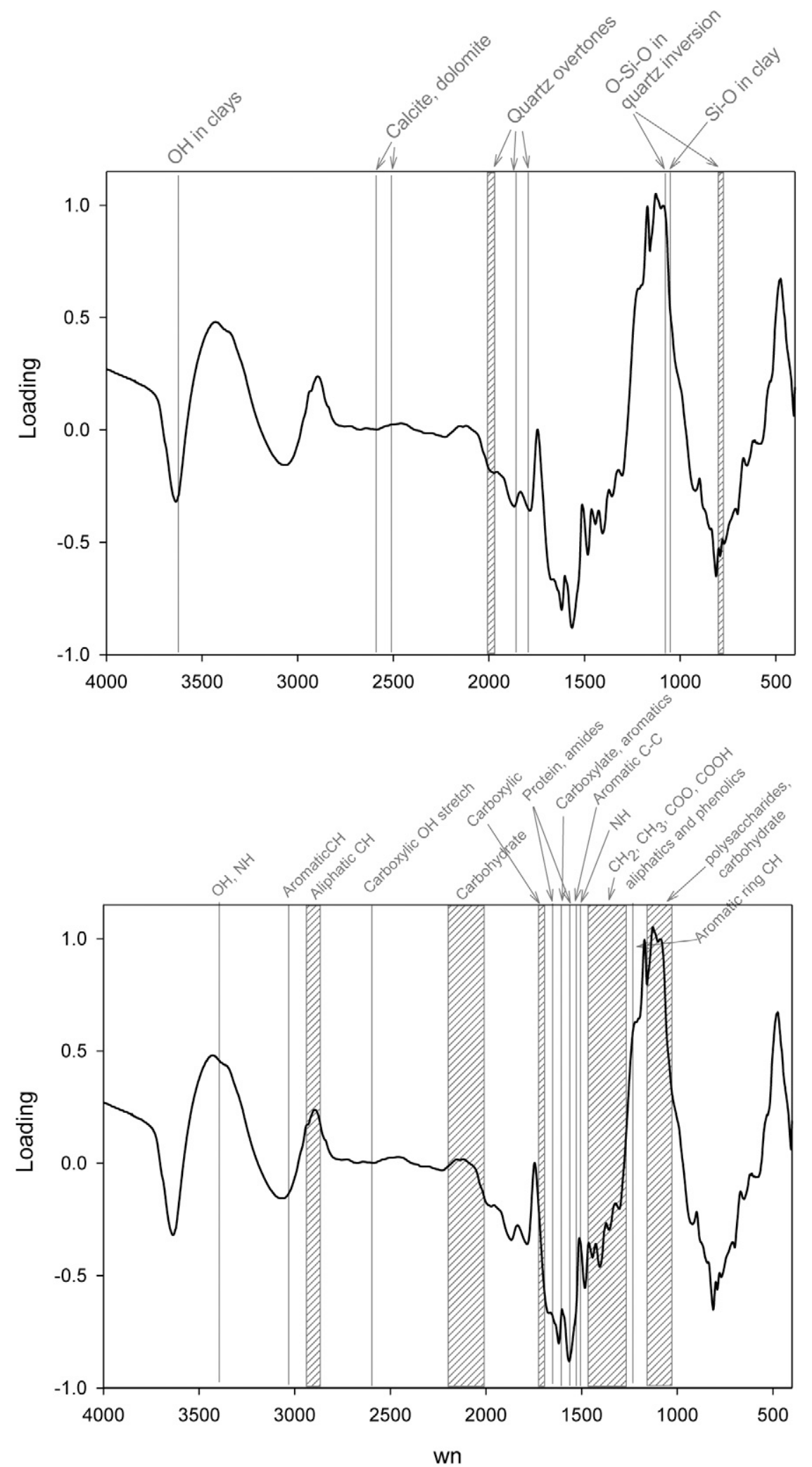

Fig. 11. Component 1 loadings for the principal components analysis shown in the light fraction PCA in Fig. 9; wn, wavenumbers in $\mathrm{cm}^{-1}$. Top graph has the mineral bands indicated, bottom graph has the organic bands. of soils that had been previously characterized by both ${ }^{14} \mathrm{C}$ (Paul et al., 2001), ${ }^{13} \mathrm{C}$ (Collins et al., 1999), and long-term incubation and fractionation (Haile-Mariam et al., 2008). It provided valuable molecular structural information to help interpret the SOM dynamics studies conducted previously on these soils. The analysis demonstrates that the spectral differences between the LF, POM silt, and clay fractions are greater than those attributable to soil type and location. Depth effects that relate to the very significant differences in previously noted MRTs for these horizons were also observed. The loss, during incubation, of spectral bands in the LF fraction associated with those from plant residues confirms the previously measured changes in $\mathrm{C} / \mathrm{N}$ ratio and the ${ }^{13} \mathrm{C}$ tracer data indicating that recent corn-derived $\mathrm{C}$ is the most labile, but also moves fairly rapidly into the older fractions. The extensive differences noted between the LF and the related POM fraction requires further study. The soil mineral absorption associated with the POM and its close relation to the silt fraction will have to be further delineated.

The fact that the spectral characteristics of clay-associated SOM, shown by tracers to be the oldest fraction, changed extensively during incubation indicates multiple interactions in what is thought to be a resistant fraction. Also puzzling are the extensive changes brought about by the deliming with weak acid. Organic constituents were affected by this treatment in addition to those expected by the loss of carbonate-spectral absorption.

The clays were separated clearly from all the other constituents by the PCA analysis of the spectra and the signals for the prairie, grassland-derived, Wisconsin samples were further separated from those of the forest-derived soils. Ashing and mathematical subtraction of the mineral signals from those of the whole soil showed that this was in part attributable to the quality of the SOM in this fraction but there may also be mineralogical differences. This is in agreement with the observations of Collins et al. (2000) that the dynamics of the originally, prairie-derived SOM are different from those of forest-derived constituents. The clay fraction showed aromatic absorption that has in the past been associated with charcoal and humification. But, both these peaks and those associated with the higher $\mathrm{N}$ content of the clays, even after correcting for fixed ammonia in the clays, require further investigation. 
There are a number of approaches for determining the molecular structure of SOM relative to its dynamics. Plante et al. (2009) analyzed soils from the same Hoytville site by using Pyrolysis-molecular beam mass spectrometry (Py-MBMS). Although, they looked at humic acid fractions and whole soils while the present study looked at particle-size fractions and whole soils, some observations can be made regarding these two studies. Both MidIR and Py-MBMS are datarich and fast, but MidIR is nondestructive. Both techniques require extensive statistical analysis, and both give a good relation to total soil C and clearly separate soils at depth. Pyrolysis-molecular beam mass spectrometry characterizes the molecular weight of heat breakdown products. It gave good resolution of humic acid fractions and cultivated vs. grassland or forest soils. Mid-infrared relies on the vibrational absorbance of functional groups of SOM. This study showed the clear resolution of the SOM signals from particlesize fractions, which differ in the age and chemistry of organic C. One advantage of MidIR over Py-MBMS is that mineral features like clays, silicates, and carbonates can be identified. This however can also be a disadvantage until the different bands have been clearly differentiated.

The techniques are complementary and both could benefit from increased use of internal standards to help quantify the data obtained. The use of multiple techniques, on similar soil samples, that have been characterized relative to their dynamics by tracers helps to look at SOM from different perspectives and also brings out the merits of the different techniques.

Many studies have now established that MidIR with multivariate analysis is a powerful tool to develop accurate calibrations for total soil C. Clearly, infrared spectra contain wealth of information about soil $\mathrm{C}$ quality that can be exploited with judicious interpretation. Our results also show that MidIR spectroscopy can be used as a screening tool to quickly distinguish different soil types. Soils with different amounts of calcareous materials can also be resolved by absorbance at $2517 \mathrm{~cm}^{-1}$.

\section{ACKNOWLEDGMENTS}

We want to thank Michelle Haddix, Michael Pappas, and Brandon Peterson for all their help with the sample preparation and laboratory analyses. Thanks to Shawel Haile-Mariam for previous research done with this sample set. This study was partially funded by a grant to E. A. Paul from the U.S. DOE, Office of Research, DE-FGO3-00ER 66297. Soil analyses presented in Table 1 were carried out at the Dep. of Crop and Soil Sciences, Michigan State University. Thanks to the Ohio State University, University of
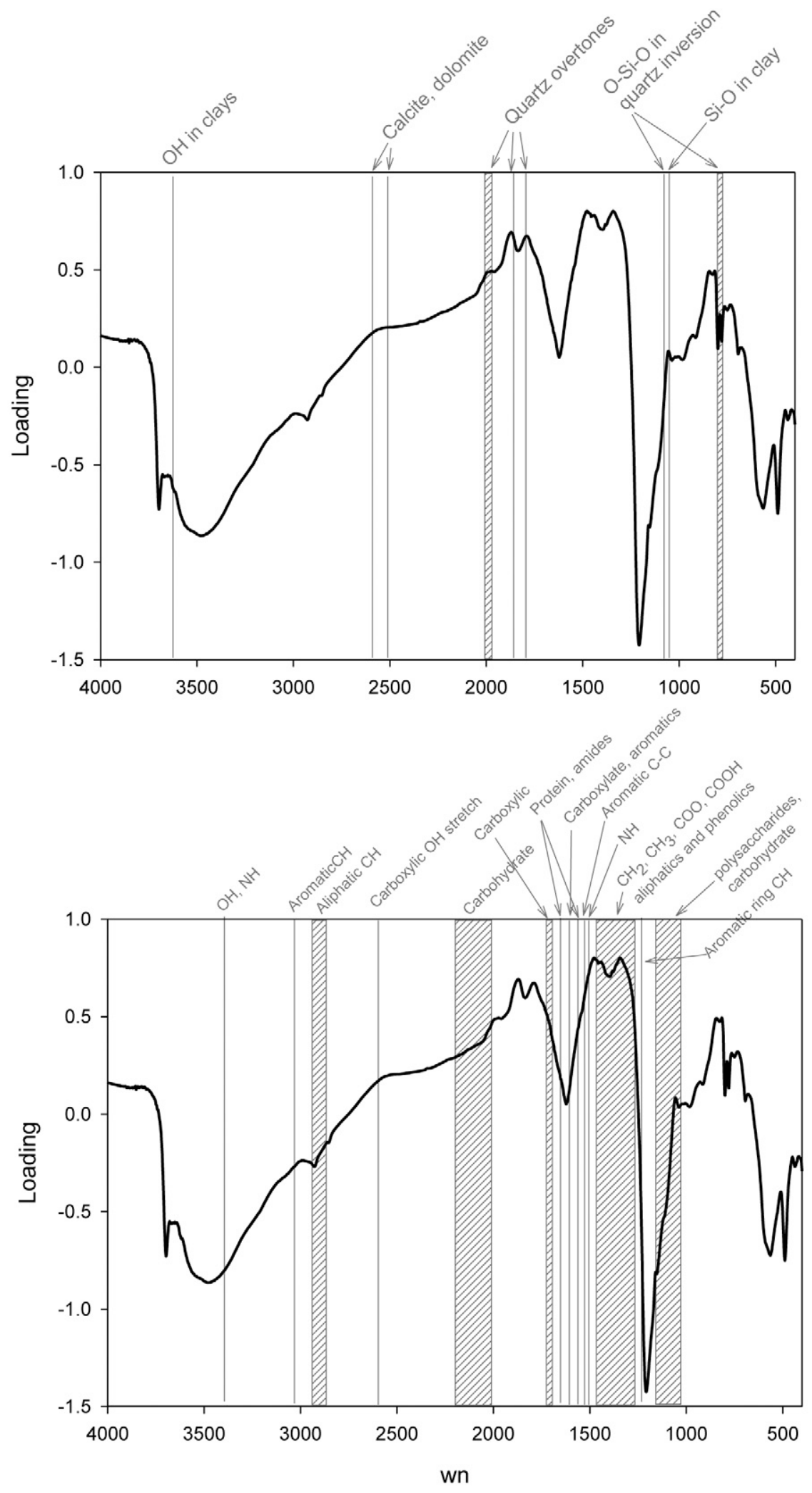

Fig. 12. Component 2 loadings for the principal components analysis shown in the clay fraction PCA in Fig. 10; wn, wavenumbers in $\mathrm{cm}^{-1}$. Top graph has the mineral bands indicated, bottom graph has the organic bands. 
Minnesota, and the KBS NSF-LTER, Michigan State University, for access to the research plots.

\section{REFERENCES}

Artz, R.R.E., S.J. Chapman, and C.D. Campbell. 2006. Substrate utilisation profiles of microbial communities in peat are depth dependent and correlate with whole soil FTIR profiles. Soil Biol. Biochem. 38:2958-2962.

Baes, A.U., and P.R. Bloom. 1989. Diffuse reflectance and transmission fourier transform infrared (DRIFT) spectroscopy of humic and fulvic acids. Soil Sci. Soc. Am. J. 53:695-700.

Bornemann, L.G.W., and W. Amelung. 2010. Particulate organic matter at the field scale: Rapid acquisition using mid-infrared spectroscopy. Soil Sci. Soc. Am. J. 74:1147-1156.

Calderón, F., G. McCarty, and J. Revees. 2006. Pyrolisis-MS and FT-IR analysis of fresh and decomposed dairy manure. J. Anal. Appl. Pyrolysis 76:14-23.

Christensen, B.T. 1987. Decomposability of organic matter in particle size fractions from field soils with straw incorporation. Soil Biol. Biochem. 19:429-435.

Collins, H.P., L.G. Bundy, D.R. Christenson, W.A. Dick, D.R. Huggins, and E.A. Paul. 1999. Soil carbon dynamics in corn-based agroecosystems: Results from carbon-13 natural abundance. Soil Sci. Soc. Am. J. 63:584-591.

Collins, H.P., E.T. Elliott, K. Paustian, L.G. Bundy, W.A. Dick, D. Huggins, A.J.M. Smucker, and E.A. Paul. 2000. Soil carbon pools and fluxes in longterm corn belt agroecosystems. Soil Biol. Biochem. 32:157-168.

Cox, R., H.L. Peterson, J. Young, C. Cusik, and E.O. Espinoza. 2000. The forensic analysis of soil organic by FTIR. Forensic Sci. Int. 108:107-116.

Haberhauer, G., and M.H. Gerzabek. 1999. Drift and transmission FT-IR spectroscopy of forest soils: An approach to determine decomposition processes of forest litter. Vib. Spectrosc. 19:413-417.

Haile-Mariam, S., H.P. Collins, S. Wright, and E.A. Paul. 2008. Fractionation and long-term laboratory incubation to measure soil organic matter dynamics. Soil Sci. Soc. Am. J. 72:370-378.

Janik, L.J., R.H. Merry, and J.O. Skjemstad. 1998. Can mid infrared diffuse reflectance analysis replace soil extractions? Aust. J. Exp. Agric. 38:681-696.
Janik, L.J., J. Skjemstad, K. Shepherd, and L. Spouncer. 2007. The prediction of soil carbon fractions using mid-infrared-partial least square analysis. Aust. J. Soil Res. 45:73-81.

Lal, R. 2004. Soil carbon sequestration impacts on global climate change and food security. Science 304:1623-1627.

McCarty, G.W., and J.B. Reeves, III. 2000. Development of rapid instrumental methods for measuring soil organic carbon. p. 371- 380. In R. Lal et al. (ed.) Assessment methods for soil carbon. Lewis Publishers, Boca Raton, FL.

McCarty, G.W., J.B. Reeves, III, V.B. Reeves, R.F. Follett, and J.M. Kimble. 2002. Mid-Infrared and near-infrared diffuse reflectance spectroscopy for soil carbon measurement. Soil Sci. Soc. Am. J. 66:640-646.

Nguyen, T., L.J. Janik, and M. Raupach. 1991. Diffuse reflectance infrared fourier transform (DRIFT) spectroscopy in soil studies. Aust. J. Soil Res. 29:49-67.

Paul, E.A., H.P. Collins, and S.W. Leavitt. 2001. Dynamics of resistant soil carbon of midwestern agricultural soils measured by naturally-occurring ${ }^{14} \mathrm{C}$ abundance. Geoderma 104:239-256.

Plante, A., K. Magrini-Bair, M.F. Vigil, and E.A. Paul. 2009. Pyrolysis-molecular beam mass spectrometry to characterize soil organic matter composition in chemically isolated fractions from differing land uses. Biogeochemistry 92:145-161.

Reeves, J.B., III, G.W. McCarty, and V.B. Reeves. 2001. Mid-Infrared diffuse reflectance spectroscopy for the quantitative analysis of agricultural soils. J. Agric. Food Chem. 49:766-772.

Sarkhot, D.V., N.B. Comerford, E.J. Jokela, J.B. Reeves, III, and W. Harris. 2007. Aggregation and Aggregate Carbon in a Forested Southeastern Coastal Plain Spodosol. Soil Sci. Soc. Am. J. 71:1779-1787.

Sollins, P., C. Swanston, M. Kleber, T. Filley, M. Kramer, S. Crow, B.A. Caldwell, K. Lajtha, and R. Bowden. 2006. Organic C and N stabilization in a forest soil: Evidence from sequential density fractionation. Soil Biol. Biochem. 38:3313-3324.

Spaccini, R., A. Piccolo, G. Haberhauer, M. Stemmer, and M.H. Gerzabek. 2001. Decomposition of maize straw in three European soils as revealed by DRIFT spectra of soil particle fractions. Geoderma 99:245-260. 